\title{
Avaliação catalítica de titanomagnetitas
}

\author{
Pereira, J. R. P. ${ }^{1}$; Gonçalves C. M..2; Fabris J. D. ${ }^{2}$; Ferreira S. A. D. ${ }^{1}$; Lelis, M. F. F'1.
}

${ }^{1}$ Departamento de Química, Universidade Federal do Espírito Santo, Vitória, ES, Brasil

${ }^{2}$ Departamento de Química, Universidade Federal de Minas Gerais, Belo Horizonte, MG, Brasil

\begin{abstract}
Resumo
As magnetitas substituídas, do tipo $\mathrm{Fe}_{3-\times} \mathrm{M}_{\times} \mathrm{O}_{4}(\mathrm{M}=$ metal) são muito promissoras no desenvolvimento de processos oxidativos do tipo Fenton heterogêneo, na decomposição de compostos aromáticos em meio aquoso, com $\mathrm{H}_{2} \mathrm{O}_{2}$. A distribuição preferencial do substituinte entre os sítios tetraédricos e octaédricos exerce grande influência nas propriedades físicas e químicas, tais como a sua utilização nos processos oxidativos avançados. Neste contexto, no presente trabalho foram sintetizadas magnetitas dopadas por titânio pelo método de coprecipitação e caracterizadas por análises químicas $\left(\mathrm{Fe}^{2+}, \mathrm{Fe}^{3+}, \mathrm{Ti}^{4+}\right)$, Difratometria de Raio-X e Espectroscopia Mossbauer. Testes preliminares mostraram que a decomposição de $\mathrm{H}_{2} \mathrm{O}_{2}$ é acelerada na medida em que se aumenta o teor de titânio na estrutura da magnetita.
\end{abstract}

Keywords (Palavras chaves): magnetitas; titânio, foto-Fenton.

\section{Introdução}

O desenvolvimento de novos processos capazes de destruir compostos aromáticos em meio aquoso tornase de suma importância e, neste caso, os processos oxidativos do tipo Fenton heterogêneo, com $\mathrm{H}_{2} \mathrm{O}_{2}$ vêm de encontro com esta problemática [1]. Estes processos são baseados na geração de radical hidroxila $(\cdot \mathrm{OH})$, de alto potencial de redução, que possibilita a oxidação não seletiva de uma variedade de compostos orgânicos transformando-os em produtos inertes $\left(\mathrm{CO}_{2}, \mathrm{H}_{2} \mathrm{O}\right.$ e ácidos minerais), fato que não ocorre com os processos convencionais de tratamento que promovem apenas transferência de fase do poluente [2].

A magnetita possui características bastante peculiares, como a presença de $\mathrm{Fe}^{2+}$ e $\mathrm{Fe}^{3+}$ e a possível substituição por alguns cátions metálicos em sua estrutura [3]. Neste trabalho foram sintetizadas magnetitas dopadas por titânio pelo método de coprecipitação e caracterizadas por análises químicas $\left(\mathrm{Fe}^{2+}, \mathrm{Fe}^{3+}, \quad \mathrm{Ti}^{4+}\right)$, Difratometria de Raio-X e Espectroscopia Mossbauer e avaliada a sua eficiência na presença de $\mathrm{H}_{2} \mathrm{O}_{2}$.

\section{Metodologia}

Síntese e Caracterização das titanomagnetitas As titanomagnetitas foram preparadas através do método de co-precipitação, baseado na síntese do precursor hidróxido-acetato férrico [4] convertido à magnetita por aquecimento em atmosfera de $\mathrm{N}_{2}$.

Foram caracterizadas por análises químicas $\left(\mathrm{Fe}^{2+}, \mathrm{Fe}^{3+}\right.$ e $\mathrm{Ti}^{4+}$ ), Difratometria de Raios-X (DRX) usando a radiação $\mathrm{K} \alpha$ do $\mathrm{Cu}(\lambda=1,5406 \AA ̊$ ) e Espectroscopia Mössbauer utilizando um espectrômetro com transdutor e gerador de função CMTE. As amostras foram diluídas com sacarose na proporção 1:2 e acondicionadas em pastilhas, utilizadas como absorvedores. As calibrações foram feitas com folha de ferro metálico e os espectros foram obtidos a temperatura ambiente, a uma velocidade de aproximadamente $10 \mathrm{~mm} \mathrm{~s}^{-1}$.

Testes de decomposição de $\mathrm{H}_{2} \mathrm{O}_{2}$

Estes testes foram realizados como uma primeira forma de se verificar a eficiência das titanomagnetitas e também de avaliar os alguns fatores que podem influenciar na decomposição do $\mathrm{H}_{2} \mathrm{O}_{2}$.

\section{Resultados e Discussão}

\section{Caracterização das titanomagnetitas}

Pode-se verificar pelo resultado da análise química (Tabela 1) que o teor de $\mathrm{FeO}$ praticamente mantêm-se constante evidenciando que 0 titânio substitui preferencialmente os íons $\mathrm{Fe}^{3+}$ na estrutura das magnetitas.

Tabela 1. Análises químicas das titanomagnetitas.

\begin{tabular}{lcccc}
\hline Amostra & $\mathrm{FeO}$ & $\mathrm{Fe}_{2} \mathrm{O}_{3}$ & $\mathrm{TiO}_{2}$ & \multicolumn{1}{c}{ Fórmula } \\
\hline MtTi1 & 24,8 & 70,1 & 5,1 & $\mathrm{Fe}^{3+}{ }_{1,96} \mathrm{Fe}^{2+}{ }_{0,76} \mathrm{Ti}^{4+}{ }_{0,15} \mathrm{O}^{2-}{ }_{4}$ \\
$\mathrm{MtTi} 2$ & 24,5 & 66,8 & 8,7 & $\mathrm{Fe}^{3+}{ }_{1,87} \mathrm{Fe}^{2+}{ }_{0,70} \mathrm{Ti}^{4+}{ }_{0,25} \mathrm{O}^{2-}{ }_{4}$ \\
$\mathrm{MtTi3}$ & 22,9 & 64,2 & 12,9 & $\mathrm{Fe}^{3+}{ }_{1,80} \mathrm{Fe}^{2+}{ }_{0,59} \mathrm{Ti} \mathrm{i}^{4+}{ }_{0,36} \mathrm{O}^{2-}{ }_{4}$ \\
\hline
\end{tabular}

Nos difratogramas de Raios- $X$ verifica-se um sutil aumento da linha de base e alargamento das reflexões aos quais correspondem aos planos (111), (220), (311), 
(222), (400), (422), (511) e (440) ao longo da série das titanomagnetitas comparando-as ao difratograma de uma magnetita pura. Isso pode ter ocorrido porque a incorporação de Ti na rede cristalina formou partículas de pequeno tamanho, já que não foi observada a presença de nenhuma outra fase cristalina no sistema.

Na Figura 1 são mostrados os espectros Mossbauer das titanomagnetitas e também da magnetita pura, obtidos a temperatura do ambiente. Apenas o espectro relativo à amostra de magnetita pura é constituído de dois sextetos, enquanto para os demais observa-se a presença de dois dupletos na parte central. Esses dupletos tornam-se mais acentuados à medida que quantidades maiores de Ti são incorporados à rede da magnetita. A possibilidade levantada foi devido à existência de partículas magnéticas muito finas e de pequeno tamanho. Analisando a razão das áreas dos sítios tetraédrico e octaédrico verifica-se que esta aumenta com o aumento do grau de dopagem, indicando a substituição do $\mathrm{Fe}^{3+}$ por titânio no sítio octaédrico, já que o teor de $\mathrm{Fe}^{2+}$ praticamente não muda ao longo da série, de acordo com os resultados obtidos através da análise química.

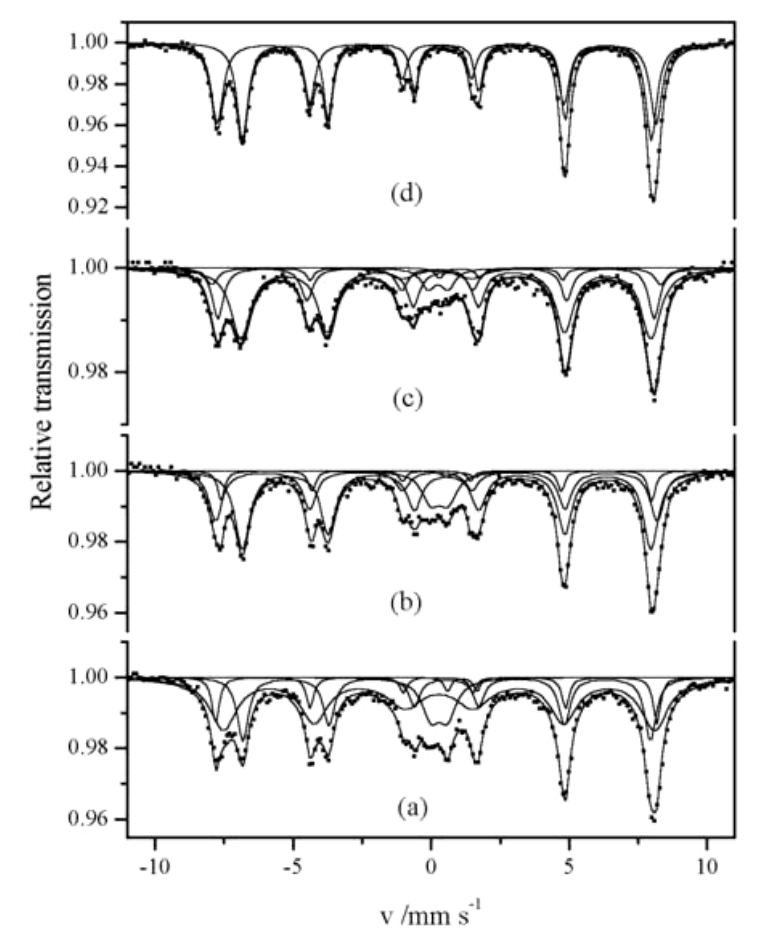

Figura 2. Espectros Mossbauer obtidos a temperatura do ambiente (a) MtTi3, MtTi2, (c) MtTi1, (d) Mt pura.

\section{Testes de degradação}

Testes preliminares mostraram que a decomposição de $\mathrm{H}_{2} \mathrm{O}_{2}$ é acelerada na medida em que se aumenta o teor de titânio na estrutura da magnetita (Figura 3). Outro fator que justifica a maior eficiência catalítica da MtTi3 é que com o aumento do teor de titânio incorporado à rede cristalina ocorre a diminuição do tamanho das partículas, como confirmados por DRX e pelos espectros Mossbauer.

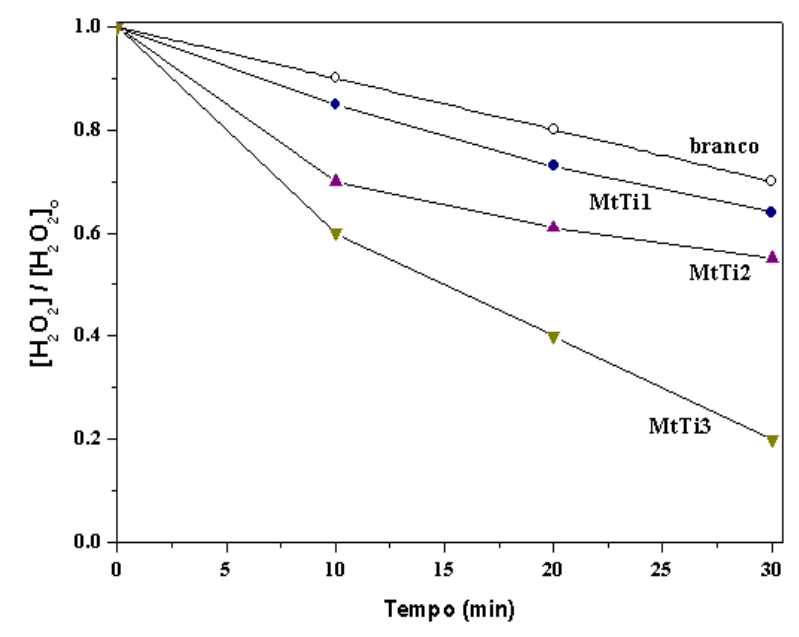

Figura 3. Decomposição de $\mathrm{H}_{2} \mathrm{O}_{2}$ em função do tempo na ausência de catalisador (branco) e na presença de titanomagnetitas.

\section{Conclusões}

Foi observada a presença de apenas uma fase, a titanomagnetitas. A Espectroscopia Mossbauer indicou que a substituição do ferro por titânio ocorreu no sítio octaédrico e que com o aumento do teor de titânio incorporado à rede ocorreu a diminuição do tamanho das partículas. A atividade catalítica das titanomagnetitas aumentou com o aumento do $\mathrm{Ti}^{4+}$ na estrutura cristalina, observada durante a decomposição do $\mathrm{H}_{2} \mathrm{O}_{2}$.

\section{Agradecimentos}

Os autores agradecem a FAPES e à FAPEMIG.

\section{Referências}

[1] NOGUEIRA, R.F.P; OLIVEIRA, M.C.; PATERLINI, W.C., Talanta, 66, pp. 86-91, 2005.

[2] COSTA, R.C.C.; LELIS, M.F.F.; LUIZ C. A. OLIVEIRA; FABRIS, J. D.; ARDISSON, JOSÉ D.; RIOS, R. V. R. A.; SILVA, C.N.; LAGO, R. M. Journal of Hazardous Materials B129 171-178, 2006.

[3] ANDRADE, A. L.; SOUZA, D. M.; PEREIRA, M. C.; FABRIS, J. D.; DOMINGUES, R. Z. Journal of Nanoscience and Nanotechnology 8, 1-5, 2008.

P.P. De Abreu Filho, E.A. Pinheiro, F. Galembeck, L.C.Labaki, Reactivity Solids 3, 241, 1987. 